\title{
Spring Flowers of the Dry Hillsides
}

\author{
by K. F. Best, Swift Current
}

As the next in our series, let's look at two native species of low-growing early-flowering plants. One is a perennial frcm the Rose family, and the other an annual from the Primrose family.

Cinquefoil is the name commonly applied to the large genus Potentilla. These often strawberry-like, mostly perennial herbs, belong to the Rose family. The name cinquefoil comes from the French cinq: five, and the Old French or medieval English foil: leaf. This refers to the five fingerlike (digitate) leaflets that characterize so many species of this genus. The scientific name of Potentilla comes from the Latin potens meaning powerful, and refers to the medicinal properties of a number of the species which contain large amounts of tannic acid as well as being notably astringent.

Generally speaking, the Potentillas have very little forage value, being classed as poor to fair for sheep, and worthless to poor for cattle. Most species produce numerous flowers and many small seeds which appear to have good viability. Once established, most cinquefoils, especially the perennials, are very tenacious and are able to withstand drought by virtue of their woody taproots.

Our Early Cinquefoil (Potentilla concinna) is one of the first spring blossoms to herald a new season. During the first week of May, or roughly two weeks after the first crocus is seen, the yellow blossoms emerge from a cluster of dark green buds. This low-growing perennial has a coarse, woody rootstock, and leaves that are either palmately or pinnately arranged, usually with five oblong or obovate leaflets. The toothed leaves are whitish on the underside but are greenish-silky above, and are from $1 / 2$ to one inch long. The yellow flowers have a cup-shaped base and are from $1 / 2$ to 1 inch in length. There are five petals and five sepals alternating with five sepal-like bracts. The fruit is a head with many achenes. It is a common plant on dry hillsides and open prairie.

Braving the early spring weather along with the Early Cinquefoil, we often find the pygmyflower (Androsace septentrionalis var. puberulenta). This low-growing annual belongs to the Primrose family. The leaves, which are less than $11 / 2$ inches long, are all basal except for a whorl of leafy bracts below each umbel of flowers. The flowers are small, with five sepals and five white petals. A common species, it is found on eroded and dry soils, and is often plentiful on stubble fields and cultivated land in the early spring. Although quite common, being so small, if often goes unnoticed.

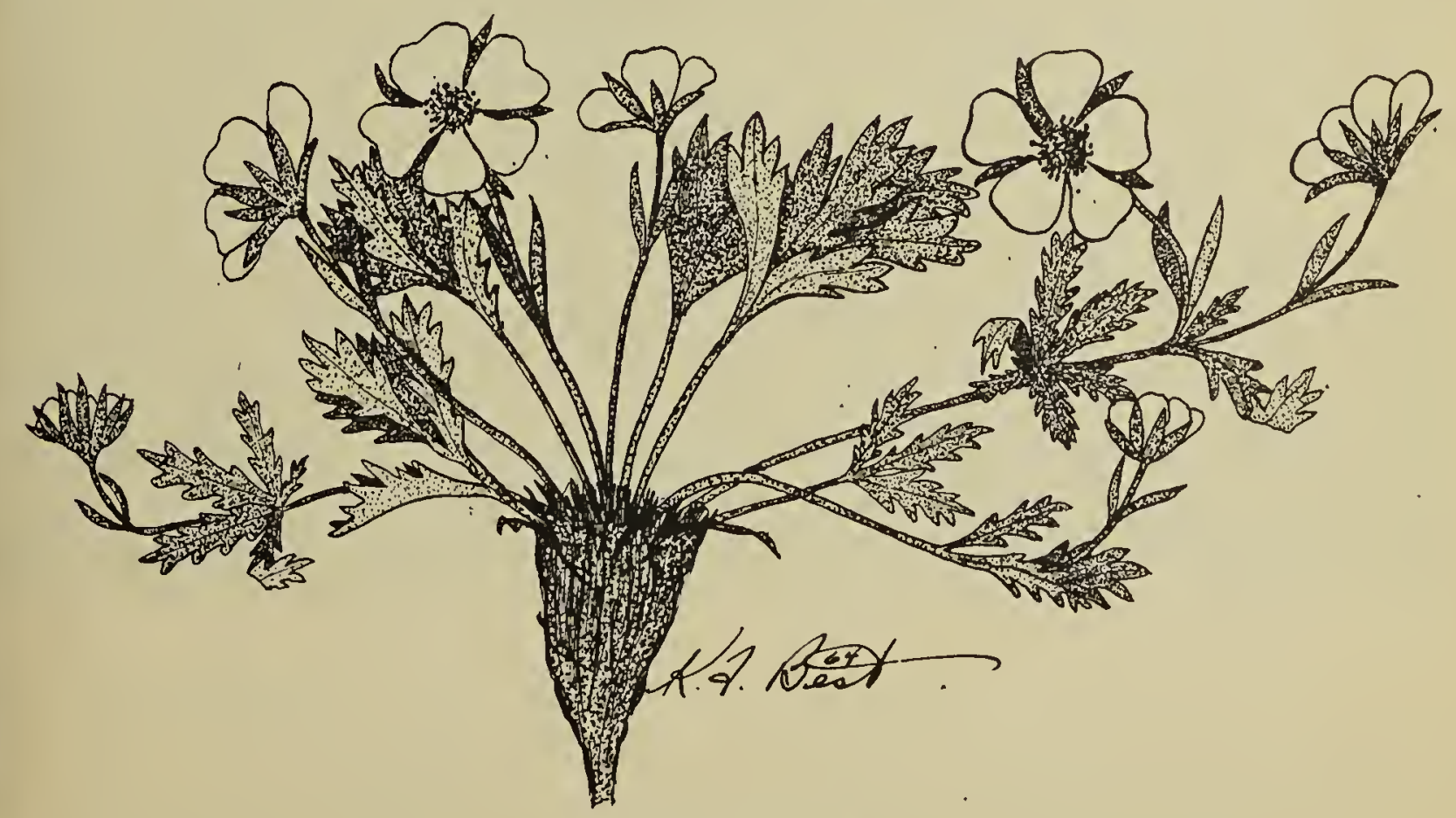

Early Cinquefoil 


\section{Pygmyflower}

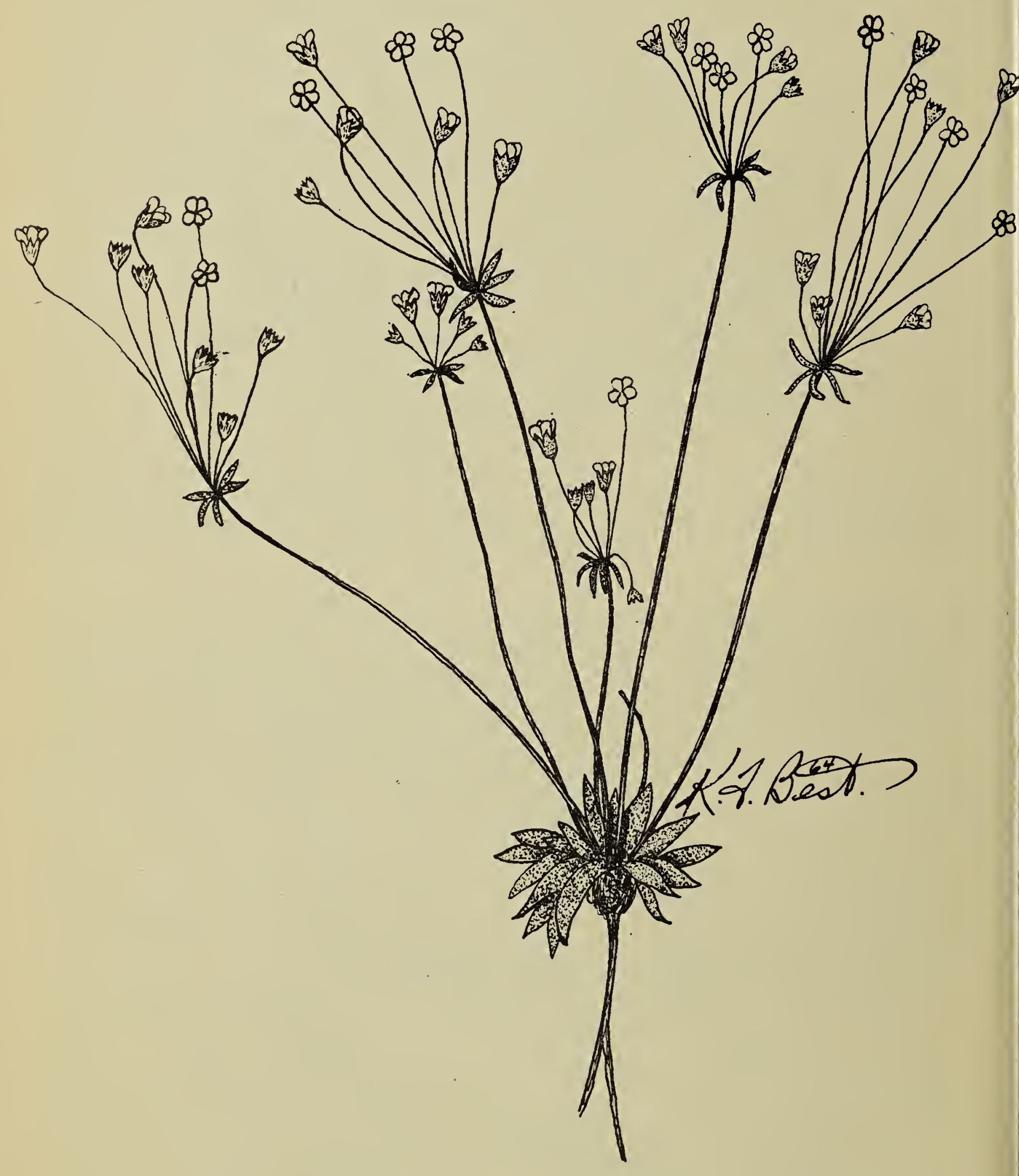

Drawing by K. F. Best

Androsace septentrionalis L. var puberulenta (Rydb.) Knuth. 


\section{White Cinquefoil}

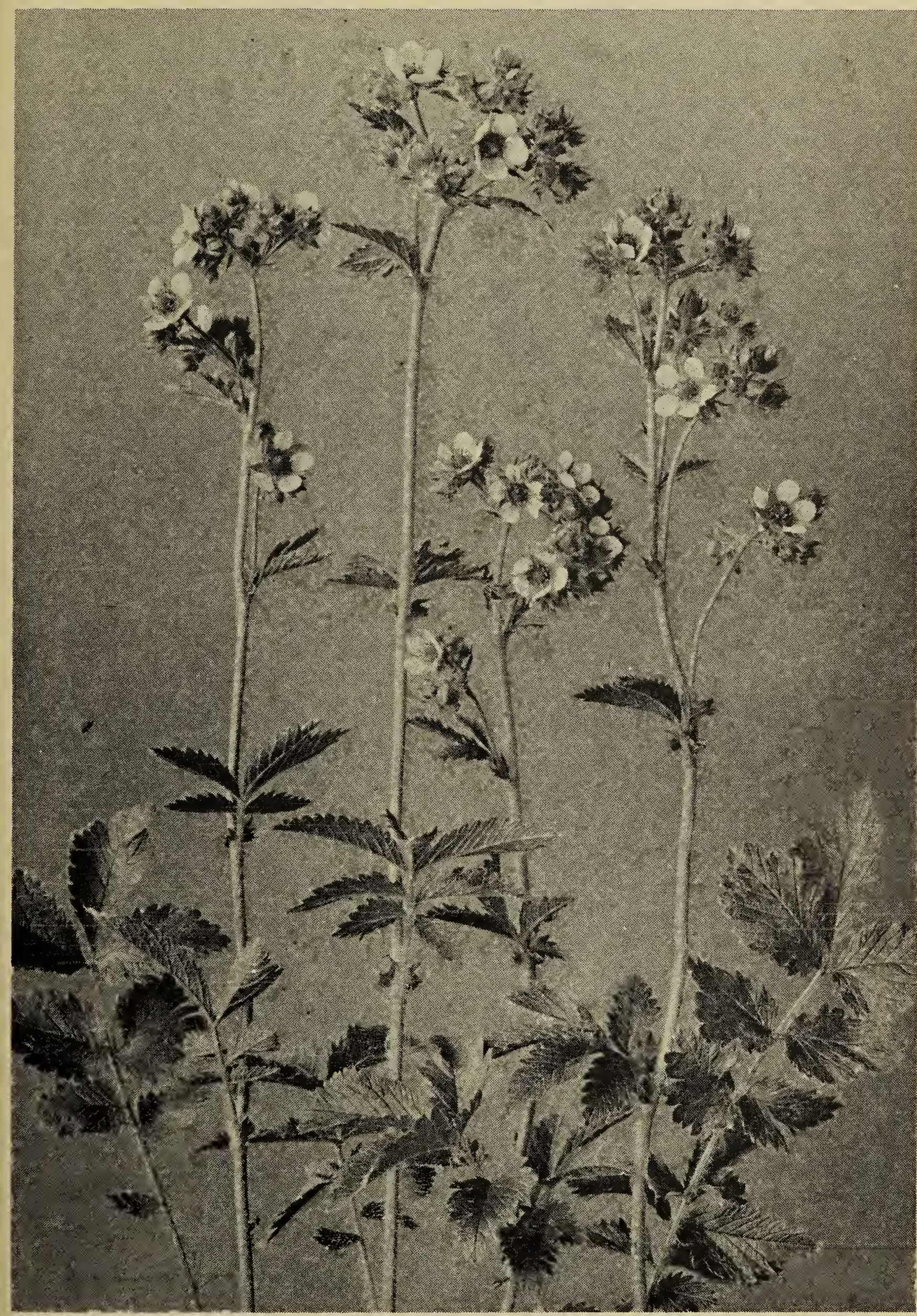

Photo by the late W. C. McCalla

Potentilla arguta Pursh

The White Cinquefoil is a plant with stiff erect stems. The flowers have white petals which distinguish it from other Potentillas which usually have fellow petals. The species is widely distributed across the plains but it is not isually abundant. 